\title{
QUANTITATIVE DETERMINATION OF THE VISCERAL PAIN THRESHOLD IN MAN
}

\author{
CHARACTERISTICS OF VISCERAL PAIN, EFFECT OF INFLAMMATION AND \\ ANALGESICS ON THE THRESHOLD, AND RELATIONSHIP OF \\ ANALGESIA TO VISCERAL SPASM
}

BY EDWARD A. GAENSLER

(From the Henderson Laboratory, Fourth Surgical Service, Boston City Hospital, Boston, Mass.)

(Submitted for publication November 15, 1950; accepted, February 16, 1951)

The development of synthetic analgesics and derivatives of morphine has focused much attention on analgesic testing methods (1). Goetzl, Burrill and Ivy in 1943 abstracted from the literature 75 different methods of quantitative measurement of the pain threshold (2). Pain producing stimuli were divided into mechanical, thermal, chemical and electrical, and all have been used on experimental animals as well as human volunteers. These various stimuli have been applied only to integumental structures, such as skin, lips, teeth and cornea $(3,4)$. It is generally recognized that visceral pain is a different sensation, elicited only by a special set of stimuli and mediated to the central nervous system through different pathways (5). Little work has been done in the field of visceral algesimetry. Our present evaluation of the effectiveness of various analgesic drugs is based partly on clinical impressions and partly on the assumption that an analysis of response to superficial pain provides an evaluation which also holds true for "deep" or visceral pain $(6,7)$.

Many of the notorious difficulties of integumental pain threshold determination apply equally to visceral pain. Added to these is the obvious difficulty of inaccessibility of visceral organs. Furthermore, viscera do not respond to the more easily quantitated thermal and electrical stimuli. They respond to only one special mechanical stimulus, that of stretch. From available data it is apparent that visceral pain responses, when obtained, vary a great deal more in intensity, quality and localization than pain responses from integumental structures. In spite of this, a number of valuable investigations has been made concerning localization of pain produced by distention of various portions of the gastro-intestinal tract with balloons.
Quantitative studies of deep analgesia were conducted by Wolff, Hardy and Goodell (6) and Harrison and Bigelow (7) using the method of Lewis, Pickering and Rothschild (8) by which pain is produced by the rhythmic contraction of ischemic muscle of the forearm. From these studies it was concluded that the effects of analgesics on deep pain are similar to those on superficial pain.

The threshold raising effects of narcotics on visceral pain were noted in trained dogs by Yonkman (9). Wolff, Hardy, and Goodell have studied qualitative effects of opiates on visceral pain in man by distending balloons in the duodenum for 40 minutes (6).

The gall bladder and biliary tract, though ordinarily inaccessible, become a fertile region for visceral pain studies after surgical drainage and intubation of any portion of this system. Localization of referred pain from the gall bladder has been studied by distending this organ during cholecystectomy $(10,11)$, by distending the gall bladder and common bile duct during abdominal operations under local anesthesia or after general anesthesia had worn off (12), and by faradic stimulation of the common bile duct through an electrode incorporated in a common duct catheter (13). Layne and Bergh studied the duration of biliary pain as related to biliary spasm by increasing the intrabiliary pressure with saline solution through a common duct tube (14), and White using the same technique investigated the effect of splanchnicectomy on biliary pain (15).

McGowan and associates observed intrabiliary pain and pressures in patients after choledochostomy by connecting the T-tube in the common bile duct to a manometric system filled with sterile saline solution $(16,17)$. From these studies they evolved criteria for removal of the T-tube. One of 
these criteria was that the "perfusion pain pressure" produced by external elevation of the hydrostatic pressure within the biliary system should be over $500 \mathrm{~mm}$. of water. They felt that pain sensations at lower hydrostatic pressures indicated residual cholangitis. McGowan and the author have utilized these post-operative studies for investigation of a variety of drugs thought to have spasmolytic action on the biliary tract (18-20). Opiates and synthetic analgesics were frequently given during the course of these studies for the production of artificial biliary and duodenal spasm. These drugs were found to raise the "perfusion pain pressure" and the elevation was roughly proportional to the potency and the dosage of the drug. This suggested the use of the T-tube as a pathway to visceral algesimetry.

\section{METHOD}

Forty patients volunteered for this study following surgical exploration and intubation of the common bile duct. Of these, 38 also had the gall bladder removed; one patient merely had an exploration and intubation of the common duct and one patient had an exploration of the common duct with a long arm of the T-tube placed through the sphincter of Oddi into the duodenum (Table I).

The original method of McGowan, Butsch and Walters, proposed for intrabiliary pressure recording was employed (16). Two weeks or more after operation, patients were placed in the supine position and the $T$-tube emerging from the abdomen was connected to a three way manometric system. One limb was connected to an infusion bottle containing sterile saline solution. This permitted filling of the entire system and the biliary ducts with solution. The second limb was connected to a short manometer with a small glass bubble as float arranged to record biliary pressures on a slowly revolving smoked drum. The third limb was connected to a long manometer graduated in $\mathrm{mm}$. which permitted reading of hydrostatic pressures when the infusion bottle was connected to the system and elevated. At times this third water manometer was replaced by a mercury manometer arranged to record pressures on the smoked drum. For all pressure recordings the patients' xyphoid process was chosen arbitrarily as the reference zero point.

The pain threshold was obtained in the following manner: The resting-pressure manometer, being too short for recording of pressures over $250 \mathrm{~mm}$. of water was momentarily cut off from the circuit and the infusion bottle was introduced to the system. The bottle was then slowly raised behind a screen to prevent patients from observing its height. Patients were asked to call out when the first painful sensation was noted. The intrabiliary pressure was recorded at this level by direct reading or by the mercury manometer on the smoked drum. The resting pressure manometer was then substituted for the infusion bottle into the circuit. After each threshold determination, patients were asked to describe the quality, intensity and location of the sensation.

Not all patients tested were suitable subjects for repeated pain threshold recordings. Of the 40 patients who volunteered only 32 could be called upon for further studies. Unsuitable subjects could be divided into three groups. Three patients experienced no sensation of any kind up to pressures of $1,000 \mathrm{~mm}$. of water. Higher pressures were never used. Sufficiently high pressures to cause pain could never be obtained in one patient where the long arm of the T-tube was in the duodenum since infusion fluid flowed into the intestine too rapidly for pressure elevation to develop. In four patients, colicky abdominal pain was easily induced by increased pressures but unlike most patients the pain did not subside together with the fall in intrabiliary pressure. In three patients, colicky pain persisted for five to 10 minutes in spite of normal intrabiliary pressures and medication was required to stop the persistent pain of the fourth patient. These patients were unsuitable for repeated pain level recordings and incidentally only these four patients were unwilling to continue with further experiments.

Resting biliary pressures were recorded for $30 \mathrm{~min}$ utes. During this time control pain thresholds were recorded at least three times. These usually checked within $30 \mathrm{~mm}$. of water (Table I). Rapid elevation of the infusion bottle tended to result in slightly higher threshold readings. In later experiments, the speed of pressure elevation was standardized to $30 \mathrm{~mm}$. per second so that even the highest threshold elevations could be obtained in 30 seconds.

After 30 minutes, the analgesic drug to be tested was given by the parenteral route. Pain threshold recordings were made 15 and 30 minutes and one, two and three hours after injection. Occasionally in cooperative patients, thresholds were determined at more frequent intervals. On other occasions experiments were prolonged to four and five hours.

Treatment of data: Both the spontaneous or resting intrabiliary pressure and the pressure sufficient to cause pain were measured in $\mathrm{mm}$. of water with the patients' xyphoid process as the zero reference point. Resting pressure elevations due to the spasmogenic effect of drugs were expressed as elevation in $\mathrm{mm}$. of water since initial resting pressures in patients without biliary sphincter obstruction varied little between 10 and $50 \mathrm{~mm}$. of water $(16,18,19)$. Pain threshold elevations due to the analgesid effects of the drugs were measured both in $\mathbf{m m}$. of water and as per cent elevation. The latter form was more useful since initial control pressures necessary to cause pain varied from 90 to $800 \mathrm{~mm}$. of water.

Another value, representing the total analgesic effect of the drug, was obtained by measuring the area under the time-action curve (6). This reflected both the threshold raising activity and the duration of action. The unit for this measure of activity was "per cent-hours."

Peak resting pressures were obtained from the highest point of the kymograph tracings. Peak pain threshold 
levels were the highest thresholds measured during a three to four hour period of study. For calculation of the average result of several patients the arithmetic mean was used.

\section{RESULTS}

Character and location of pain: Hydrostatic distention of the biliary ducts with pressures up to $800 \mathrm{~mm}$. of water caused some pain sensation in 36 of 40 patients (Table I). The quality and intensity of the pain was described as sharp, stabbing or colicky by 17 patients and was called dull or just an "ache" by 17 other patients. Only two patients noted discomfort which they could not actually call pain with no further increase of this unpleasant sensation up to pressures of $1,000 \mathrm{~mm}$. of water.

The sensation was well localized in 27 patients, usually in the right upper quadrant of the abdomen (23 patients) and occasionally in the epigastric region (4 patients). Five subjects reported pin point localization at a point just below the costal margin in the midclavicular line. The sensation had a more vague distribution in nine patients; it was referred to the entire abdomen by three and to the upper part of the abdomen by six. Some radiation to the back was noted by nine patients; this radiation was never well localized and usually referred to the right upper part of the back. Pain chiefly on the left side over the precordium or radiating down the arm was never reported.

There appeared to be no relationship between the quality and intensity of the preoperative pain and the type of pain sensation reported with these experiments. There was a definite relationship

TABLE I

Location and character of induced biliary pain and its relation to preoperative pain

\begin{tabular}{|c|c|c|c|c|c|c|c|c|c|}
\hline & Age & Sex & $\begin{array}{l}\text { Duration } \\
\text { of intu- } \\
\text { bation }\end{array}$ & of & $\begin{array}{l}\text { Postopera- } \\
\text { tive pain } \\
\text { threahold }\end{array}$ & $\begin{array}{c}\text { Final } \\
\text { pain } \\
\text { threshold }\end{array}$ & Location of preoperative pain & $\begin{array}{l}\text { Experimer } \\
\text { loc }\end{array}$ & Pain type \\
\hline $\begin{array}{l}1 \\
2 \\
3 \\
4 \\
5 \\
6 \\
7 \\
8 \\
9 \\
10 \\
11 \\
12 \\
13 \\
14 \\
15 \\
16 \\
17 \\
18 \\
19 \\
20 \\
21 \\
22 \\
23 \\
24 \\
25 \\
26 \\
27 \\
28 \\
29 \\
30 \\
31 \\
32 \\
33 \\
34 \\
35 \\
36 \\
37 \\
38 \\
39 \\
40\end{array}$ & $\begin{array}{l}29 \\
58 \\
71 \\
55 \\
50 \\
23 \\
62 \\
40 \\
32 \\
55 \\
66 \\
67 \\
66 \\
67 \\
53 \\
37 \\
56 \\
44 \\
57 \\
64 \\
38 \\
34 \\
53 \\
41 \\
39 \\
53 \\
57 \\
38 \\
59 \\
54 \\
66 \\
29 \\
52 \\
40 \\
43 \\
40 \\
53 \\
30 \\
41 \\
36\end{array}$ & $\begin{array}{l}\text { F } \\
\text { M } \\
\text { F } \\
\text { F. } \\
\text { F } \\
\text { M } \\
\text { F } \\
\text { F } \\
\mathbf{M} \\
\mathbf{F} \\
\mathbf{F} \\
\mathbf{M} \\
\mathbf{F} \\
\mathbf{F} \\
\mathbf{M} \\
\mathbf{M} \\
\mathbf{M} \\
\mathbf{F} \\
\mathbf{F} \\
\mathbf{M} \\
\mathbf{F} \\
\mathbf{F} \\
\mathbf{F} \\
\mathbf{M} \\
\mathbf{F} \\
\mathbf{F} \\
\mathbf{F} \\
\mathbf{F} \\
\mathbf{M} \\
\mathbf{F} \\
\mathbf{F} \\
\mathbf{F} \\
\mathbf{M} \\
\mathbf{F} \\
\mathbf{F} \\
\mathbf{F} \\
\mathbf{F} \\
\mathbf{F} \\
\mathbf{F}\end{array}$ & $\begin{array}{l}3 \text { months } \\
50 \text { days } \\
3 \text { months } \\
2 \text { months } \\
40 \text { days } \\
49 \text { days } \\
26 \text { days } \\
29 \text { days } \\
43 \text { days } \\
17 \text { days } \\
22 \text { days } \\
22 \text { days } \\
63 \text { days } \\
6 \text { months } \\
18 \text { days } \\
68 \text { days } \\
11 \text { months } \\
14 \text { days } \\
43 \text { days } \\
40 \text { days } \\
70 \text { days } \\
7 \text { months } \\
52 \text { days } \\
4 \text { months } \\
5 \text { months } \\
22 \text { days } \\
42 \text { days } \\
24 \text { days } \\
55 \text { days } \\
14 \text { days } \\
25 \text { days } \\
62 \text { days } \\
18 \text { days } \\
21 \text { days } \\
14 \text { days } \\
26 \text { days } \\
23 \text { days } \\
17 \text { days } \\
14 \text { days } \\
\text { ? }\end{array}$ & $\begin{array}{r}5 \\
6 \\
6 \\
7 \\
7 \\
7 \\
4 \\
9 \\
4 \\
4 \\
4 \\
1 \\
7 \\
3 \\
1 \\
4 \\
1 \\
1 \\
8 \\
2 \\
1 \\
7 \\
4 \\
1 \\
7 \\
2 \\
1 \\
3 \\
1 \\
2 \\
7 \\
10 \\
3 \\
3 \\
1 \\
7 \\
7 \\
7 \\
1 \\
1\end{array}$ & $\begin{array}{c}440-450 \\
350 \\
700 \\
620-650 \\
700 \\
90-100 \\
400-430 \\
320-330 \\
380 \\
310-330 \\
450-460 \\
- \\
260-270 \\
280-300 \\
- \\
160-180 \\
- \\
1,000+ \\
400-410 \\
220-230 \\
- \\
600-620 \\
590-600 \\
1,000+ \\
200-210 \\
600-610 \\
7- \\
700-710 \\
-800 \\
280-290 \\
140-150 \\
600 \\
700 \\
550 \\
320-330 \\
300 \\
1,000+ \\
290-300\end{array}$ & \begin{tabular}{|c|c}
$620-630$ \\
500 \\
$700-720$ \\
$700-710$ \\
700 \\
$260-265$ \\
$700-720$ \\
600 \\
510 \\
$400-430$ \\
470 \\
- \\
$290-300$ \\
400 \\
$500-520$ \\
470 \\
- \\
- \\
$490-500$ \\
$240-250$ \\
700 \\
700 \\
$620-630$ \\
- \\
$200-220$ \\
$600-610$ \\
710 \\
- \\
800 \\
$300-320$ \\
300 \\
$660-670$ \\
700 \\
$5-$ \\
$560-670$ \\
400 \\
$310-320$ \\
- \\
-
\end{tabular} & $\begin{array}{l}\text { Epigastrium and back } \\
\text { Right upper quadrant } \\
\text { Right upper quadrant } \\
\text { None, nausea, vomiting } \\
\text { Right upper quadrant } \\
\text { Right upper quadrant } \\
\text { Generalized abdominal } \\
\text { None, vomiting and jaundice } \\
\text { Entire abdomen } \\
\text { Painless jaundice } \\
\text { Upper abd., rad. to back } \\
\text { Right upper abdomen } \\
\text { Upper abdomen } \\
\text { Sharp, rt. upper abdomen } \\
\text { Rt. upper abd., rad. to back } \\
\text { Post-gastrectomy jaundice } \\
\text { Operative ligation of C.D. } \\
\text { Generalized abdominal } \\
\text { Colicky rt. flank pain } \\
\text { Right upper quadrant } \\
\text { Rt. upper abd., rad. to back } \\
\text { Jaundice, clay col. stools } \\
\text { Epigastric } \\
\text { Epigastric } \\
\text { Right upper quadrant } \\
\text { Gen. abd., rad. to back } \\
\text { Sharp, rt. upper abdomen } \\
\text { Epigastric } \\
\text { Substernal distress } \\
\text { Midabdominal } \\
\text { Epigastric } \\
\text { Right upper quadrant } \\
\text { Epigastric } \\
\text { Lower abdomen } \\
\text { Epigastric burning } \\
\text { Painless, jaundice, nausea } \\
\text { Upper abdomen } \\
\text { Rt. upper abd., rad. to back } \\
\text { Generalized abdominal } \\
\text { Nausea, vomiting } \\
\text { Sulom }\end{array}$ & $\begin{array}{l}\text { Epigastric and infrascap. } \\
\text { Right upper quadrant } \\
\text { Right upper quadrant } \\
\text { Right upper quadrant } \\
\text { Right upper quadrant } \\
\text { Right upper quadrant } \\
\text { RUQ and epigastric } \\
\text { Right subcostal } \\
\text { RUQ and infrascapular } \\
\text { Upper abdomen } \\
\text { RUQ radiating to back } \\
\text { Lasting pain spasm } \\
\text { Upper abdomen } \\
\text { Right upper quadrant } \\
\text { RUQ radiating to back } \\
\text { Right subcostal } \\
\text { T-tube in duodenum } \\
\text { No pain to } 1,000 \text { mm. } \\
\text { Right upper quadrant } \\
\text { Upper abdomen } \\
\text { Right upper quadrant } \\
\text { Epigastric } \\
\text { Epigastric } \\
\text { No pain to } 1,000 \text { mm. } \\
\text { Epigastric } \\
\text { Upper abd. and back } \\
\text { Lasting pain spasm } \\
\text { RUQ and epigastric } \\
\text { Lasting pain spasms } \\
\text { Upper abdomen } \\
\text { RUQ and epigastric } \\
\text { Rt. upper abd. and back } \\
\text { Rt. subcostal and epig. } \\
\text { Right upper quadrant } \\
\text { Lasting pain spasms } \\
\text { Generalized abdominal } \\
\text { Right upper quadrant } \\
\text { Rt. upper abd. and back } \\
\text { No pain to } 1,000 \text { mm. } \\
\text { Right subcostal }\end{array}$ & $\begin{array}{l}\text { Sharp } \\
\text { Ache } \\
\text { Stabbing } \\
\text { Dull } \\
\text { Dull } \\
\text { Discomf. } \\
\text { Dull } \\
\text { Sharp } \\
\text { Sharp } \\
\text { Dull } \\
\text { Sharp } \\
\text { Dull } \\
\text { Stabbing } \\
\text { Dull } \\
\text { Sharp } \\
\\
\text { Stabbing } \\
\text { Discomf. } \\
\text { Sharp } \\
\text { Dull } \\
\text { Dull } \\
\text { Sharp } \\
\text { Dull } \\
\text { Dull } \\
\text { Dull } \\
\text { Sharp } \\
\text { Sharp } \\
\text { Dull } \\
\text { Sharp } \\
\text { Dull } \\
\text { Dull } \\
\text { Sharp } \\
\text { Dull }\end{array}$ \\
\hline
\end{tabular}


between the preoperative and postoperative localization of the pain: of six patients who named pain radiating to the back as their chief complaint on entry to the hospital, five later reported back pain as part of the sensation due to distention of the biliary ducts. Chapman and associates have previously reported on this relationship (21). Repeated distention of the biliary system in the same patients resulted in identical localization, intensity and quality of pain both during the course of the same study and on different days. The intensity, quality and localization of the pain was not altered by the rapidity with which the pressure was elevated.

The pain threshold: A great deal of variation was found in the level of the pain threshold from one patient to another. The pain threshold of all patients 14 days after introduction of the T-tube varied from 90 to $800 \mathrm{~mm}$. of water and at the time of tube removal from 200 to $800 \mathrm{~mm}$. of water (Table I). There was less variation of the threshold in the same patients tested at various times. In 15 subjects, mostly those with high initial threshold, the pain level varied no more than $30 \mathrm{~mm}$. during the entire time of intubation, as long as five months in one instance. In the remaining 21 patients, the thresholds slowly increased during the course of observation. A decrease of the threshold was never noted. A slowly increasing threshold over the course of weeks was interpreted as a sign of subsiding cholangitis (16). Sarkisian and McGowan have found a good relationship between the level of the pain threshold and the bacterial count of the bile (22). Similarly inflammation was found to lower the pain threshold during tests of skin pain (23).

In spite of these variations, the biliary pain threshold was found useful as a measure of the effect of analgesic and narcotic substances because variations of threshold in the same patient during the course of a single study were very small (Table I). In 10 subjects repeated threshold determinations on the same day varied by less than $5 \mathrm{~mm}$. of water while in the remaining 24 patients the variation was less than $30 \mathrm{~mm}$. of water, usually no more than $10 \mathrm{~mm}$. In addition, in 15 subjects the threshold varied very little from one day to another often for many weeks and even months (Table I). These patients were well suited for comparative study of the action of several drugs.
TABLE II

Individual threshold determinations of six patients during 12 hours

\begin{tabular}{|c|c|c|c|c|c|c|c|}
\hline \multicolumn{2}{|c|}{ Time } & \multicolumn{6}{|c|}{ Patient No. } \\
\hline Hours & Min. & 28 & 31 & 32 & 36 & 37 & 38 \\
\hline $\begin{array}{l}0 \\
0 \\
0 \\
0 \\
1 \\
1 \\
2 \\
2 \\
3\end{array}$ & $\begin{array}{r}0 \\
10 \\
20 \\
30 \\
0 \\
30 \\
0 \\
30 \\
0\end{array}$ & $\begin{array}{l}700 \\
700 \\
705 \\
710 \\
705 \\
705 \\
710 \\
710 \\
710\end{array}$ & $\begin{array}{l}280 \\
280 \\
290 \\
290 \\
290 \\
290 \\
295 \\
290 \\
295\end{array}$ & $\begin{array}{l}140 \\
165 \\
145 \\
140 \\
140 \\
140 \\
145 \\
140 \\
145\end{array}$ & $\begin{array}{l}560 \\
560 \\
565 \\
565 \\
560 \\
570 \\
570 \\
570 \\
570\end{array}$ & $\begin{array}{l}340 \\
360 \\
370 \\
375 \\
370 \\
\mathbf{3 4 5} \\
\mathbf{3 4 0} \\
\mathbf{3 5 0} \\
\mathbf{3 5 0}\end{array}$ & $\begin{array}{l}305 \\
310 \\
310 \\
310 \\
310 \\
320 \\
320 \\
320 \\
320\end{array}$ \\
\hline 6 & $\begin{array}{l}0 \\
15\end{array}$ & $\begin{array}{l}695 \\
695\end{array}$ & $\begin{array}{l}300 \\
295\end{array}$ & $\begin{array}{l}150 \\
150\end{array}$ & $\begin{array}{l}555 \\
570\end{array}$ & $\begin{array}{l}340 \\
350\end{array}$ & $\begin{array}{l}310 \\
310\end{array}$ \\
\hline $\begin{array}{r}8 \\
8\end{array}$ & $\begin{array}{c}\cdots \\
15\end{array}$ & $\begin{array}{l}710 \\
710\end{array}$ & $\begin{array}{l}290 \\
290\end{array}$ & $\begin{array}{l}150 \\
145\end{array}$ & $\begin{array}{l}560 \\
570\end{array}$ & $\begin{array}{l}350 \\
360\end{array}$ & $\begin{array}{l}320 \\
320\end{array}$ \\
\hline $\begin{array}{l}11 \\
11 \\
11 \\
12\end{array}$ & $\begin{array}{c}0 \\
15 \\
30 \\
0\end{array}$ & $\begin{array}{l}710 \\
705 \\
705 \\
710\end{array}$ & $\begin{array}{l}310 \\
300 \\
300 \\
295\end{array}$ & $\begin{array}{l}155 \\
150 \\
150 \\
145\end{array}$ & $\begin{array}{l}560 \\
565 \\
570 \\
570\end{array}$ & $\begin{array}{l}\mathbf{3 7 5} \\
\mathbf{3 7 0} \\
\mathbf{3 7 0} \\
\mathbf{3 7 0}\end{array}$ & $\begin{array}{l}315 \\
320 \\
320 \\
325\end{array}$ \\
\hline \multirow{2}{*}{\multicolumn{2}{|c|}{$\begin{array}{l}\text { Mean, mm. of water } \\
\text { Standard deviation, } \mathbf{m m} \text {. } \\
\text { Coefficient of variation, } \\
\text { per cent }\end{array}$}} & $\begin{array}{l}706 \\
\pm 5.1\end{array}$ & $\begin{array}{c}293 \\
\pm 7.1\end{array}$ & $\begin{array}{l}147 \\
\pm 5.1\end{array}$ & $\begin{array}{l}565 \\
\pm 5.0\end{array}$ & $\begin{array}{c}358 \\
\pm 12.6\end{array}$ & $\begin{array}{l}316 \\
\pm 5.6\end{array}$ \\
\hline & & 0.67 & 2.43 & 3.82 & 0.88 & 3.52 & 1.77 \\
\hline
\end{tabular}

Near the completion of this study it appeared desirable to obtain data for statistical expression of threshold variations in individual patients. Six patients were studied by repeated threshold determinations over the course of 12 hours (Table II). At intervals these patients returned to the ward for meals and visiting hours and studies were then continued. In all, 17 control readings were obtained. The mean pain thresholds varied from 146.7 to $705.6 \mathrm{~mm}$. of water in these six patients. The smallest standard deviation was $\pm 5.1 \mathrm{~mm}$. for a mean pressure of $705.6 \mathrm{~mm}$. and the largest standard deviation encountered was $\pm 12.6 \mathrm{~mm}$. for a mean pressure of $357.9 \mathrm{~mm}$. The smallest coefficient of variation was 0.67 per cent and the largest was 3.82 per cent (Table II). These figures from six selected patients compared favorably with data obtained by the Hardy-Wolff-Goodell technique of individual patients studied from time to time. Uniformity of pain threshold from individual to individual obtained by thermal radiation of the skin could not be duplicated with visceral pain threshold determinations.

The end point: The threshold end point was usually definite particularly in patients who experienced sharp or stabbing pain. A little more care was necessary to determine the exact end point in those patients who experienced merely a dull ache. In the 32 patients found suitable for visceral pain threshold studies the pain sensation 


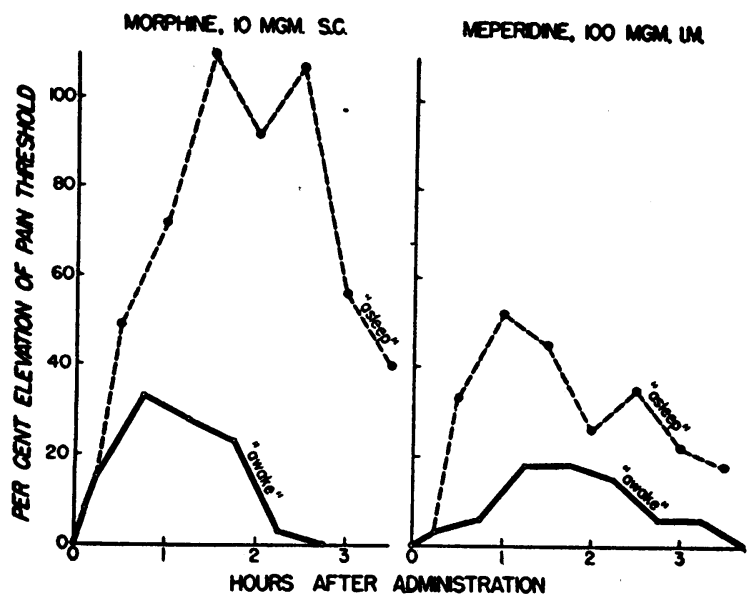

Fig. 1. Perception of and Reaction to Visceral Pain

For "awake" threshold determinations patients were aroused before the test and asked to signify the first unpleasant sensation due to elevation of the intrabiliary pressure. For the "asleep" curves the pressure was elevated without warning to the inattentive, drowsy or sleeping patients.

subsided almost instantly as the pressure was reduced. In no case was there pain for more than 15 seconds with each threshold determination.

Experiences with pain produced by inflation of balloons in the esophagus, duodenum, colon and ureter suggest that the biliary tree is the most suitable hollow viscus for determination of pain thresholds. Precise hydrostatic measurements of the pain threshold in these other organs were not possible in our experience because these organs responded with peristaltic waves to even slight pressure elevations in the balloon. These con- tractions were reflected in the pressure readings and steady high pressures within the balloon lumen could therefore not be maintained. Relative to the size of its lumen the common bile duct has by far the thinnest muscular wall of any of the above named organs. Here peristaltic movements are usually not observed during recording of resting pressures. Even with the more sensitive and rapidly responding microphone-condenser electromanometer the only pressure changes recorded were due to changes in abdominal pressure with cardiac systole, respirations and voluntary contractions of the abdominal musculature.

During routine experiments patients were invariably warned of the approaching threshold determination to assure their alertness and then the saline infusion bottle was raised behind the screen. Experiments were also planned during which the patient was notified of the pressure elevation about to occur at the end of 15 and 30 minutes and one, two and three hours and at irregular intervals between these periods the infusion bottle was raised without the patient's knowledge. Figure 1 illustrates two such time action curves of two different patients. Prior to administration of the drug there was no difference between the "awake" and "asleep" thresholds. Fifteen minutes after injection there was a definite elevation of the threshold both after $10 \mathrm{mgm}$. of morphine and $100 \mathrm{mgm}$. of meperidine. The two thresholds were still the same. One hour after morphine, there was an "awake" threshold elevation of 30 per cent while the "asleep" threshold elevation was 72 per cent.

TABLE III

Visceral analgesic activity of narcotics and acetylsalicylic acid

\begin{tabular}{|c|c|c|c|c|c|}
\hline Drug & $\begin{array}{c}\text { No. of } \\
\text { patients }\end{array}$ & $\begin{array}{l}\text { No. of } \\
\text { studies }\end{array}$ & $\begin{array}{l}\text { Mean peak } \\
\text { threshold } \\
\text { elevation, } \\
\text { mm. water }\end{array}$ & $\begin{array}{l}\text { Mean peak } \\
\text { threshold } \\
\text { elevation, } \\
\text { per cent }\end{array}$ & $\begin{array}{c}\text { Analgesic } \\
\text { activity, } \\
\text { "per cent- } \\
\text { hours" }\end{array}$ \\
\hline $\begin{array}{l}\text { Morphine sulfate, } \\
10 \text { mgm., s.c. } \\
\text { Codeine sulfate, } \\
60 \text { mgm., s.c. } \\
\text { Dihydromorphinone } \\
\text { hydrochloride, } 3 \text { mgm., s.c. } \\
\text { Methyldihydromorphinone } \\
\text { hydrochloride, } 7.5 \text { mgm., s.c. } \\
\text { Methadone, } \\
7.5 \text { mgm., s.c. } \\
\text { Meperidine hydrochloride, } \\
100 \text { mgm., c.m. } \\
\text { Acetylsalicylic acid, } \\
0.6-1.2 \text { Gm., oral. }\end{array}$ & $\begin{array}{r}30 \\
22 \\
11 \\
7 \\
10 \\
32 \\
12\end{array}$ & $\begin{array}{r}40 \\
27 \\
11 \\
7 \\
10 \\
50 \\
13\end{array}$ & $\begin{array}{r}233 \\
53 \\
162 \\
162 \\
153 \\
102 \\
0\end{array}$ & $\begin{array}{c}56.4 \\
11.9 \\
41.9 \\
46.4 \\
33.2 \\
22.9 \\
0\end{array}$ & $\begin{array}{r}140 \\
40 \\
112 \\
98 \\
168 \\
70 \\
0\end{array}$ \\
\hline
\end{tabular}


The peak threshold elevations for these two types of determinations were 33 and 110 per cent, respectively, after morphine and 18 and 53 per cent, respectively, after meperidine. Three hours after injection of morphine the "awake" threshold was no longer elevated while the "asleep" threshold was still 40 per cent above the control level.

The first type of threshold, called "awake" was the true perception threshold since the end point was given by alerted patients' first recognition of a painful sensation. The second or "asleep" value was obtained after drowsy, inattentive or even asleep patients were sufficiently stimulated by the pain to make their complaint known. This was therefore not a true threshold but a measure of the analgesic action together with the physiologic and psychologic response to the hypnotic, euphoria producing and other effects of the narcotic. It is apparent that these other effects contribute greatly to the clinical effectiveness of narcotics on visceral pain. Furthermore hypnosis, euphoria and inattentiveness were in evidence for a much longer period of time than the analgesic effect.

Effect of analgesic drugs on the visceral pain threshold: Satisfactory time action curves were obtained from 32 patients on 158 occasions. No ill effects were encountered during or after these studies. Two patients experienced chills about three hours after threshold studies and cholangiography. The temperature, elevated at that time, was found normal three hours later and remained normal thereafter.

The analgesic activity of drugs was compared in two groups of patients. In the first all the patients studied were included (Table III). In the second only seven patients were included whose threshold response was measured for all seven drugs of this series (Figure 2). A true comparison of the effectiveness of the various analgesics could best be made in the latter group since individual initial pain thresholds varied widely and the analgesic effect was dependent to some extent on the magnitude of the initial threshold. These seven patients were among the last ones studied since some of the newer synthetic analgesics had not been available previously; they were patients who showed a good pain threshold end point and whose control thresholds varied little from day to day; lastly they were chosen because the T-tube drainage was continued for a sufficient period of



Fig. 2. Mean Time-Action Curves in Per Cent Elevation of Pain Threshold for Seven Patients after Various Narcotics aNd Acetylsalicylic AcId

time to allow for evaluation of all drugs. Studies were prolonged to four and one-half hours in this group.

Morphine sulfate: Ten mgm. of this agent were given subcutaneously to 30 patients on 40 occasions (Table III). A marked elevation of the visceral pain threshold was observed every time. The onset of action was rapid. The threshold was elevated after 15 minutes in every instance and occasional studies seven minutes after injection showed increase of pressure tolerance at that time. The peak action was observed 15 minutes after injection in 10 per cent of the time-action curves, after 30 minutes in 70 per cent and after one hour in 20 per cent. Some action was still discernible after three hours in all but one patient. The mean peak elevation from the control level was $233 \mathrm{~mm}$. of water or 56.4 per cent and the total analgesic effect was 140 per cent-hours (Table III).

The pain thresholds after morphine of the seven patients in the second group are shown in Table IV. Definite threshold elevation was still present in all patients at the end of four hours. The mean peak elevation of 53 per cent was found 30 minutes after injection.

The mean time-action curves for all drugs for the seven patients of the second group are shown in Figure 2. With the dosage schedule used, morphine caused the highest peak effect and its duration of action was surpassed only by methadone.

Codeine sulfate: This drug was given subcutaneously in $60 \mathrm{mgm}$. doses to 22 patients on $27 \mathrm{oc}$ - 
casions (Table III). A threshold elevation resulted in all but one patient. The onset of action was slower than after other drugs. Only twothirds of the time-action curves indicated activity 15 minutes after injection. The height of the effect was reached 30 minutes after administration on 10 occasions and one hour after injection on 16 occasions. The duration of action was briefer than that of morphine. Only 72 per cent of the time-action curves showed threshold elevation after three hours. However, all elevations after codeine were so small that the method may well not have been sufficiently delicate to demonstrate slight effects at both ends of the time-action curves. The mean peak elevation for all patients was 53 $\mathrm{mm}$. of water or 11.9 per cent. The total analgesic action of 40 per cent-hours was the smallest encountered.

Comparison of the responses of the seven patients treated with all drugs showed relatively greater variations than those of any other group (Table IV). The mean time-action curve (Figure 2) indicated that codeine caused the smallest threshold elevation of any drug studied. There was no discernible effect at the end of four hours.

Dihydromorphinone hydrochloride ("Dilaudid") : Three mgm. of this drug were given subcutaneously to 11 patients (Table III). The first response, like that after morphine was noted after seven minutes. The peak response was obtained 30 minutes after injection in four patients and one hour after treatment in the remainder. In the

TABLE IV

Visceral pain threshold elevation in $\mathbf{m m}$. of water of seven individual patients after various narcotics

\begin{tabular}{|c|c|c|c|c|c|c|c|c|c|c|c|c|c|c|}
\hline \multirow{3}{*}{ Patient No. } & \multicolumn{14}{|c|}{ Time after administration } \\
\hline & \multicolumn{3}{|c|}{ Minules } & \multicolumn{4}{|c|}{ Hours } & \multicolumn{3}{|c|}{ Minutes } & \multicolumn{4}{|c|}{ Hours } \\
\hline & $\mathbf{0}$ & 15 & 30 & 1 & 2 & 3 & 4 & $\mathbf{0}$ & 15 & 30 & 1 & 2 & 3 & 4 \\
\hline & \multicolumn{7}{|c|}{ Morphine sulfate, $10 \mathrm{mgm}$. } & \multicolumn{7}{|c|}{ Methyldihydromorphinone $\mathrm{HCl}, 7.5 \mathrm{mgm}$. } \\
\hline \multirow[t]{2}{*}{$\begin{array}{c}22 \\
25 \\
31 \\
32 \\
36 \\
37 \\
38 \\
\text { Mean per cent } \\
\text { elevation }\end{array}$} & $\begin{array}{r}620 \\
190 \\
300 \\
140 \\
560 \\
330 \\
300 \\
\\
0\end{array}$ & $\begin{array}{r}640 \\
360 \\
400 \\
300 \\
620 \\
400 \\
480 \\
\\
31\end{array}$ & $\begin{array}{r}680 \\
410 \\
480 \\
380 \\
620 \\
540 \\
630 \\
\\
53\end{array}$ & $\begin{array}{l}680 \\
480 \\
500 \\
370 \\
510 \\
560 \\
550 \\
\\
50\end{array}$ & $\begin{array}{l}670 \\
390 \\
460 \\
340 \\
600 \\
540 \\
500 \\
\\
43\end{array}$ & $\begin{array}{r}630 \\
340 \\
400 \\
280 \\
570 \\
400 \\
360 \\
\\
22\end{array}$ & $\begin{array}{r}630 \\
250 \\
360 \\
230 \\
570 \\
370 \\
330 \\
10\end{array}$ & $\begin{array}{r}200 \\
300 \\
300 \\
560 \\
320 \\
310 \\
600 \\
0\end{array}$ & $\begin{array}{r}320 \\
380 \\
370 \\
610 \\
460 \\
500 \\
570 \\
24\end{array}$ & $\begin{array}{r}390 \\
450 \\
350 \\
610 \\
520 \\
580 \\
670 \\
\\
38\end{array}$ & $\begin{array}{r}420 \\
450 \\
350 \\
610 \\
530 \\
460 \\
780 \\
39\end{array}$ & $\begin{array}{r}350 \\
410 \\
330 \\
600 \\
480 \\
400 \\
770 \\
29\end{array}$ & $\begin{array}{r}320 \\
400 \\
330 \\
580 \\
400 \\
390 \\
560 \\
\\
15\end{array}$ & $\begin{array}{r}250 \\
330 \\
330 \\
550 \\
330 \\
370 \\
540 \\
\\
4\end{array}$ \\
\hline & \multicolumn{7}{|c|}{ Codeine sulfate, $60 \mathrm{mgm}$. } & \multicolumn{7}{|c|}{ Methadone, 7.5 mgm. } \\
\hline $\begin{array}{c}22 \\
25 \\
31 \\
32 \\
36 \\
37 \\
38 \\
\text { Mean per cent } \\
\text { elevation }\end{array}$ & $\begin{array}{r}600 \\
210 \\
320 \\
160 \\
550 \\
360 \\
300 \\
0\end{array}$ & $\begin{array}{r}620 \\
260 \\
360 \\
200 \\
550 \\
430 \\
300 \\
9\end{array}$ & $\begin{array}{r}640 \\
290 \\
400 \\
220 \\
590 \\
360 \\
410 \\
\\
16\end{array}$ & $\begin{array}{r}650 \\
300 \\
400 \\
240 \\
590 \\
360 \\
390 \\
\\
17\end{array}$ & $\begin{array}{r}620 \\
240 \\
380 \\
190 \\
580 \\
370 \\
390 \\
11\end{array}$ & $\begin{array}{r}620 \\
220 \\
360 \\
180 \\
580 \\
360 \\
370 \\
8\end{array}$ & $\begin{array}{r}620 \\
200 \\
330 \\
150 \\
570 \\
350 \\
340 \\
2\end{array}$ & $\begin{array}{r}700 \\
210 \\
290 \\
150 \\
550 \\
310 \\
300 \\
0\end{array}$ & $\begin{array}{r}730 \\
260 \\
320 \\
170 \\
580 \\
400 \\
480 \\
17\end{array}$ & $\begin{array}{l}750 \\
320 \\
400 \\
320 \\
590 \\
480 \\
580 \\
37\end{array}$ & $\begin{array}{r}770 \\
380 \\
480 \\
360 \\
610 \\
500 \\
570 \\
46\end{array}$ & $\begin{array}{r}775 \\
420 \\
460 \\
300 \\
610 \\
520 \\
570 \\
46\end{array}$ & $\begin{array}{r}780 \\
390 \\
450 \\
210 \\
600 \\
450 \\
550 \\
37\end{array}$ & $\begin{array}{r}740 \\
360 \\
390 \\
190 \\
570 \\
430 \\
510 \\
\\
27\end{array}$ \\
\hline & \multicolumn{7}{|c|}{ Dihydromorphinone $\mathrm{HCl}, 3$ mgm. } & \multicolumn{7}{|c|}{ Meperidine $\mathrm{HCl}, 100$ mgm. } \\
\hline $\begin{array}{c}22 \\
25 \\
31 \\
32 \\
36 \\
37 \\
38 \\
\text { Mean per cent } \\
\text { elevation }\end{array}$ & $\begin{array}{r}600 \\
210 \\
300 \\
160 \\
550 \\
370 \\
300 \\
0\end{array}$ & $\begin{array}{r}620 \\
340 \\
430 \\
280 \\
575 \\
420 \\
460 \\
26\end{array}$ & $\begin{array}{l}660 \\
380 \\
470 \\
350 \\
600 \\
520 \\
500 \\
40\end{array}$ & $\begin{array}{r}670 \\
400 \\
480 \\
360 \\
600 \\
520 \\
480 \\
\\
41\end{array}$ & $\begin{array}{r}630 \\
320 \\
460 \\
340 \\
560 \\
520 \\
450 \\
32\end{array}$ & $\begin{array}{r}610 \\
230 \\
420 \\
280 \\
560 \\
440 \\
500 \\
\\
22\end{array}$ & $\begin{array}{r}610 \\
200 \\
350 \\
260 \\
560 \\
430 \\
470 \\
6\end{array}$ & $\begin{array}{r}600 \\
200 \\
340 \\
210 \\
550 \\
375 \\
300 \\
\\
0\end{array}$ & $\begin{array}{r}660 \\
340 \\
460 \\
300 \\
670 \\
480 \\
400 \\
\\
29\end{array}$ & $\begin{array}{r}650 \\
350 \\
490 \\
350 \\
580 \\
480 \\
480 \\
\\
31 .\end{array}$ & $\begin{array}{r}650 \\
340 \\
470 \\
340 \\
590 \\
470 \\
470 \\
\\
29\end{array}$ & $\begin{array}{r}600 \\
300 \\
440 \\
310 \\
580 \\
450 \\
430 \\
\\
21\end{array}$ & $\begin{array}{r}590 \\
210 \\
400 \\
245 \\
540 \\
400 \\
320 \\
5\end{array}$ & $\begin{array}{r}600 \\
210 \\
375 \\
225 \\
540 \\
380 \\
320 \\
\\
2\end{array}$ \\
\hline
\end{tabular}


dosages used, dihydromorphinone was superior to methyldihydromorphinone in both peak per cent elevation and total analgesic action. Inspection of individual time-action responses (Table IV) and of their mean curve (Figure 2) revealed fairly uniform action in different patients. The peak of the curve was lower than that of morphine but at three hours their action was identical.

Methyldihydromorphinone hydrochlorid $e^{1}$ ("Metopon"): This morphine derivative was given in $7.5 \mathrm{mgm}$. doses to the seven patients of Table IV. Responses differed little from those obtained with dihydromorphinone. The onset of action was fairly rapid. In one patient the peak was reached in 15 minutes. Of the six others, three showed the maximal response after 30 minutes and three after one hour (Table IV). The shape of the time-action curve was almost identical to that of dihydromorphinone.

Methadone: Ten patients were treated with 7.5 mgm. of this agent (Table III). Although the first analgesic action was noted as soon after injection as after other drugs, the peak activity was definitely delayed. Only one patient showed maximal action after 30 minutes, four showed the peak after one hour, four after two hours and one after three hours. Since methadone was the only drug tested which showed useful activity at the end of four hours threshold determinations were continued beyond four hours in three patients. Useful activity of methadone at five hours was noted in all three and a mean elevation of 8 per cent was still found after six hours. The peak elevation for all ten patients was $153 \mathrm{~mm}$. of water-less than that after morphine and its derivatives. Comparison of the individual (Table IV) and average time-action curves (Figure 2) of seven patients showed the peak action of methadone to be inferior only to morphine. At the end of two hours, methadone was superior to morphine and at three and four hours the activity of this drug was about twice that of morphine and its derivatives.

Meperidine hydrochloride ("Demerol"): Onehundred mgm. of this drug were given intramuscularly to all 32 patients on 50 occasions

1 Metopon hydrochloride powder for parenteral use was obtained through the kindness of Dr. Nathan B. Eddy, Committee on Drug Addiction and Narcotics of the National Research Council.
(Table III). It was the most rapidly acting drug of this series. Maximal action was noted after 15 minutes in one-half of the time-action curves while the remainder showed peaks 30 minutes after injection. Meperidine was also the shortest acting drug. Ten curves showed no activity after two hours and one-half of the tests showed no threshold elevation after three hours. The mean peak elevation of $102 \mathrm{~mm}$. of water or 22.9 per cent and the total analgesic action of 70 per centhours were the lowest encountered.

Acetylsalicylic acid: Twelve patients were given 0.6 to $1.2 \mathrm{Gm}$. of acetylsalicylic acid by mouth (Table III). There was no variation from the control thresholds in any instance other than small changes in either direction usually found on repeated control determinations. Sodium salicylate given in comparable doses parenterally to four patients produced no greater changes in the pain threshold than those observed after parenteral administration of sterile saline solution. The composite time-action curve for seven patients (Figure 2) showed changes both above and below the control level which were within the limits of accuracy of the technique.

Relationship of dosage to analgesia: Four patients who were subjected to prolonged biliary drainage and whose control thresholds varied little from day to day received morphine and meperidine in increasing doses.

Time-action curves for one patient who received morphine and another after meperidine are shown in Figure 3. Increases in the lower dosage



Fig. 3. Time-Action Curves in Per Cent Elevation of Pain Threshold following Increasing Doses of Morphine and Meperiding 
TABLE $\mathbf{v}$

Relationship of dosage and visceral analgesia

\begin{tabular}{|c|c|c|c|c|c|c|c|}
\hline \multicolumn{4}{|c|}{ Morphine sulfate } & \multicolumn{4}{|c|}{ Meperidine hydrochloride } \\
\hline $\begin{array}{l}\text { Dose, } \\
\text { mgm. }\end{array}$ & $\begin{array}{l}\text { Analgesia in } \\
\text { per cent-hours }\end{array}$ & $\begin{array}{l}\text { Dose } \\
\text { ratio }\end{array}$ & $\begin{array}{c}\text { Analgesia } \\
\text { ratio }\end{array}$ & $\begin{array}{l}\text { Doee, } \\
\text { mgm. }\end{array}$ & $\begin{array}{l}\text { Analgesia in } \\
\text { per cent-hours }\end{array}$ & $\begin{array}{l}\text { Dose } \\
\text { ratio }\end{array}$ & $\begin{array}{c}\text { Analgesia } \\
\text { ratio }\end{array}$ \\
\hline $\begin{array}{r}4 \\
8 \\
10 \\
16 \\
20 \\
30\end{array}$ & $\begin{array}{r}22 \\
86 \\
140 \\
269 \\
301 \\
329\end{array}$ & $\begin{array}{l}1 \\
2 \\
2.5 \\
4 \\
5 \\
7.5\end{array}$ & $\begin{array}{c}1 \\
4 \\
6.4 \\
12.4 \\
13.9 \\
15.2\end{array}$ & $\begin{array}{r}25 \\
50 \\
100 \\
200\end{array}$ & $\begin{array}{r}43 \\
114 \\
172 \\
239\end{array}$ & $\begin{array}{l}1 \\
2 \\
4 \\
8\end{array}$ & $\begin{array}{l}1 \\
2.7 \\
4.1 \\
5.6\end{array}$ \\
\hline
\end{tabular}

ranges caused marked elevations of pain threshold. While $4 \mathrm{mgm}$. of morphine produced a peak threshold increase of 18 per cent, double the amount increased the peak to 52 per cent, and $16 \mathrm{mgm}$., again double the amount, raised the peak to 118 per cent above the control level. Further increases of the dose to 20 and $30 \mathrm{mgm}$. caused no higher threshold elevations than $16 \mathrm{mgm}$. The only effect of the largest doses was a prolongation of the action: no analgesic effect was noted at the end of four hours with doses up to $16 \mathrm{mgm}$. An appreciable threshold elevation was noted at the end of four hours with $20 \mathrm{mgm}$. and some action was detected after six hours with $30 \mathrm{mgm}$.

Time-action curves with increasing doses of meperidine showed a similar pattern of response. Doubling the dose from 25 to $50 \mathrm{mgm}$. caused a twofold increase of peak threshold elevation. Doubling the dose from 100 to $200 \mathrm{mgm}$. caused no increase of the peak action but prolonged the action considerably beyond four hours.

Dosages with corresponding per cent-hours and ratio of dosage with ratio of per cent-hours are shown in Table V. Increases in the lower ranges of morphine caused relatively much greater total analgesic action. Doubling the dose of $4 \mathrm{mgm}$. produced a fourfold increase of total analgesia and doubling the dose from 8 to $16 \mathrm{mgm}$. tripled the analgesic action. Further increases were relatively ineffective. Doubling $16 \mathrm{mgm}$. increased the total analgesic action by only 22 per cent from 269 to 329 per cent-hours. Increasing quantities of meperidine caused closely corresponding increases of total analgesic action up to $100 \mathrm{mgm}$. Double this last amount caused a further increase of analgesia of only 39 per cent. Actual values of the two studies could not be compared since they were done on different patients with different initial pain thresholds. In spite of our limiting pressures to $1,000 \mathrm{~mm}$. of water, it was never possible to obliterate the pain sensation even with the largest doses of morphine.

Relationship of level of initial pain threshold and the analgesic effect: It was shown that in different patients the initial pain threshold varied from 90 to $800 \mathrm{~mm}$. of water (Table I). It soon became apparent that in patients with initially low thresholds a relatively greater rise in pain threshold from analgesic drugs could be obtained than in patients with initially high thresholds. This was true whether the threshold raising action was expressed as elevation in $\mathrm{mm}$. of water or as per cent elevation.

Initial pain thresholds and peak pain thresholds after $10 \mathrm{mgm}$. of morphine of 40 individual timeaction curves are shown in Figure 4. With initial thresholds of 100 to $300 \mathrm{~mm}$. of water, elevations due to morphine by 400 and even $500 \mathrm{~mm}$. were



Fig. 4. Peak Threshold Elevations in MM. of Water DUe to $10 \mathrm{MgM}$. OF Morphine

Results of 40 studies arranged in increasing order of initial (control) thresholds. 
not uncommon. With the highest initial thresholds of 500 to $700 \mathrm{~mm}$. of water, threshold elevations due to morphine were considerably lower. Many were less than $100 \mathrm{~mm}$. and most not over $200 \mathrm{~mm}$. The mean threshold elevation of nine patients with initial thresholds between 90 and $290 \mathrm{~mm}$. was $340 \mathrm{~mm}$. The mean elevation of 16 patients with initial thresholds of 600 to $800 \mathrm{~mm}$. was $125 \mathrm{~mm}$.

This same phenomenon observed in a single patient who was studied with $100 \mathrm{mgm}$. meperidine from two to four weeks after operation is illustrated in Figure 5. Two weeks after operation, the initial pain threshold of $320 \mathrm{~mm}$. rose to a peak of $550 \mathrm{~mm}$. after meperidine. This rise of $230 \mathrm{~mm}$. represents a 72 per cent elevation as indicated by the arrow. Further studies 17,18 and 21 days after operation showed slowly increasing initial pain thresholds and a decreasing effect of the same dose of meperidine. The initial pain threshold 28 days after operation had risen to $600 \mathrm{~mm}$. The increase to $670 \mathrm{~mm}$. after meperidine represented only a 12 per cent elevation of pain threshold.

Patients were further grouped according to their initial pain threshold level and the elevation of threshold due to morphine, $10 \mathrm{mgm}$., meperidine, $100 \mathrm{mgm}$., and codeine, $60 \mathrm{mgm}$., were placed in the various groups (Figure 6). Other anal-

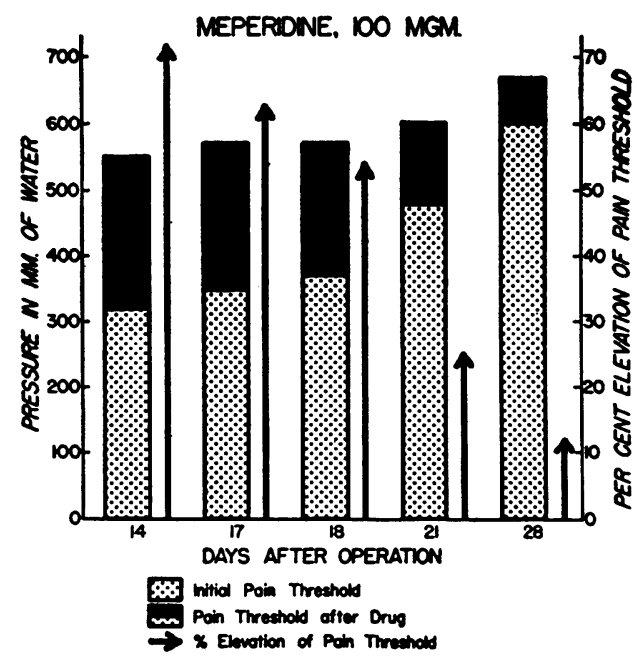

Fig. 5. Intrial Pain Thresholds and Peak ThreshOLDS IN MM. OF WATER AFTER 100 MGM. OF MEPERIDINE of one Patient Studied at Intervals from 14 to 28 Days after Operation

Arrows indicate per cent pain threshold elevation due to the medication.

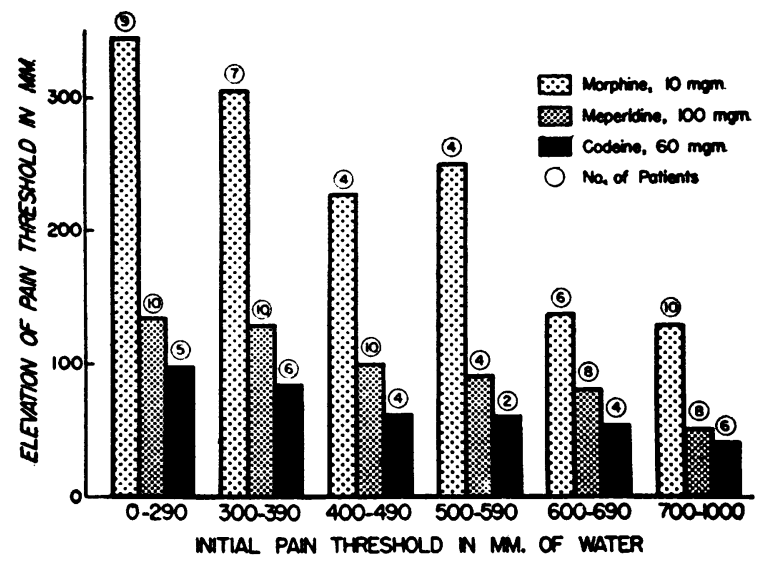

Fig. 6. Peak Pain Threshold Elevations in MM. of Water following Morphine, Meperidine and Codeine, Grouped According to Magnitude of Initial (Control) Pain Threshold

gesics were omitted because of an insufficient number of patients in each group. Here, again, as in individual patients, there was a marked decrease of threshold-elevating activity with control thresholds of increasing magnitude. In the group of patients with control pain thresholds of 90-290 mm., morphine caused a mean rise of pain thresholds of $340 \mathrm{~mm}$., meperidine of $130 \mathrm{~mm}$. and codeine of $100 \mathrm{~mm}$. In the last group with initial thresholds from 700 to $1,000 \mathrm{~mm}$., the three elevations due to morphine, meperidine and codeine were 125,50 and $40 \mathrm{~mm}$. of water. Narcotics were more effective both relatively and absolutely if the initial visceral pain threshold was low because of inflammation. If the presumption that the early low thresholds are due to cholangitis is correct these findings show a good confirmation of observations made by Schumacher with thermal radiation on inflamed skin (23).

Placebos and the visceral pain threshold: At the onset of these experiments it was suggested that the striking rise of the pain threshold after parenteral injection of analgesic drugs may in part be due to the psychologic effects of the injection. Patients were therefore chosen who had had several previous studies with large doses of potent analgesics. These studies were conducted in the usual manner except that after three initial threshold determinations $1 \mathrm{cc}$. of sterile saline solution was injected subcutaneously (Figure 7A). A very slight rise of the pain threshold $(25 \mathrm{~mm}$. or 8 per cent) was noted after 15 minutes and the 

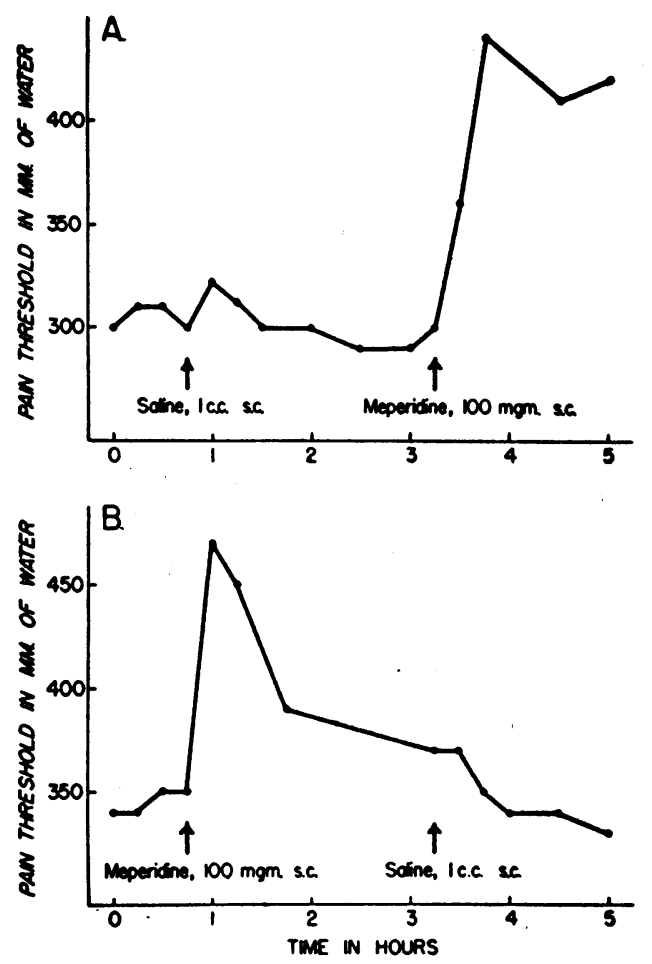

Fig. 7. The Effect of Parenteral Placebos on the Visceral Pain Threshold

A. Saline solution followed in two and one half hours by meperidine; B. Meperidine and two and one half hours later saline solution.

threshold then returned to the control level and remained there for three hours. At the end of this time $100 \mathrm{mgm}$. meperidine were injected with a resultant pressure elevation of $70 \mathrm{~mm}$. (23 per cent) after 15 minutes and $140 \mathrm{~mm}$. (47 per cent) after 30 minutes (Figure 7A). Another patient was given $100 \mathrm{mgm}$. of meperidine and two and one half hours later, after the effect of the drug had nearly disappeared, $1 \mathrm{cc}$. of sterile saline solution (Figure 7B). Here there was no increase whatever in the pain threshold after the placebo but a further fall of the threshold as the last traces of the meperidine effect disappeared. From these and six other studies with similar results it was concluded that parenteral administration of placebos did not cause an elevation of the visceral pain threshold. Furthermore, increases of thresholds in suggestible patients were smaller than comparable threshold responses of skin pain (24).

Relationship of visceral analgesia to visceral spasm: The constipating effect of opium was utilized therapeutically many hundred years before its value as a central nervous system depressant was recognized. This effect is common to all the phenanthrene derivatives of opium and is in great part due to lessened motility and increased tone of the gastro-intestinal musculature. This spasmogenic activity on the gastro-intestinal and urinary tracts and the biliary tree constitutes an undesirable side effect in those instances where morphine and codeine are used for their narcotic effect. It was hoped that the appearance of synthetic analgesics would bring a solution to this problem. However, it was shown that both the new synthetic analgesics methadone and meperidine and the morphine derivatives dihydromorphinone and methyldihydromorphinone cause spasm of the small intestine and biliary tree of man $(18,19)$. The rise of intrabiliary resting pressure which invariably follows the administration of opiates is chiefly due to spasm of the second portion of the duodenum with occlusion of the sphincter of Oddi (16). The rise in pressure has been shown to be proportional to the severity of the $\operatorname{spasm}(18,19)$.

The present method of visceral pain threshold



Fig. 8. Kymograph Tracing of Intrabiliary Resting Pressure in MM. of Water and of Pain ThreseOLd in MM. OF Mercury following Subcutanbous IsJection of 10 MGM. OF Morphine

Three inhalations of amyl nitrite caused a prompt but brief fall in the intrabiliary pressure and had no effect on the pain threshold. The base line $(0)$ is at the level of the xyphoid with the patient in the supine position. Time marker: three minutes. 
determination offered a good opportunity for simultaneous quantitative estimation of visceral spasm.

Resting intrabiliary pressures were always recorded during intervals between pain threshold determinations. Occasionally pain threshold levels in $\mathrm{mm}$. of mercury and resting pressures in $\mathrm{mm}$. of water were recorded on the same smoked drum (Figure 8).

The onset of the analgesic effect was always accompanied by a gradual rise of intrabiliary pres-

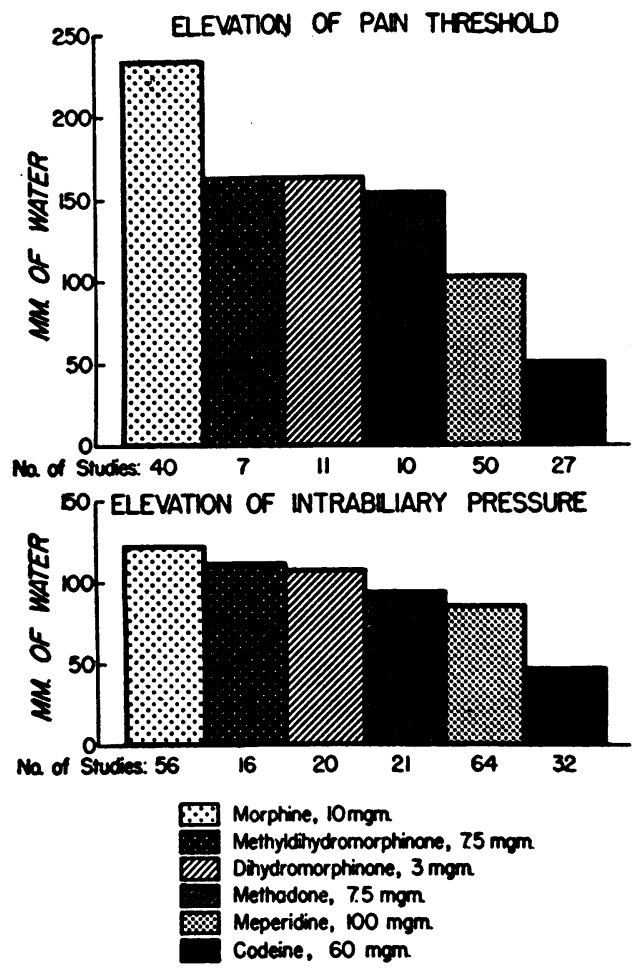

Fig. 9. Mean Peak Pain Threshold Elevations and Mean Peak Intrabiliary Resting Pressures in Ma. of Water after Various Narcotics

sure, and the elevation of this pressure was roughly proportional to the elevation of pain threshold (Figure 8). This applied to drugs of varying effectiveness as well as to the same drug given in varying doses. Figure 9 (top) shows the mean peak pain threshold elevations in $\mathrm{mm}$. of water following injection of the six narcotics studied. The same figure (bottom) shows the peak resting pressure elevation after administration of these same drugs. The order of effectiveness of these drugs for both narcosis and spasmogenesis was the same and the ratio of effectiveness of the various agents was similar.

From these data, it is evident that every drug studied which possessed visceral analgesic qualities also caused visceral spasm. The reverse was true also: every drug which was shown to cause biliary and duodenal spasm also had analgesic properties. This is an unexpected and perhaps not significant finding. The analgesic qualities of these agents are due entirely to their action on the central nervous system while their spasmogenic effects are due entirely to local action on smooth muscle (25).

\section{DISCUSSION}

Comparison of the effectiveness of various analgesic drugs is difficult because beneficial results depend to such a great extent on the dosage used. Frequently, doses of different agents, necessary to produce the same effect, have been compared. This is misleading since toxic effects of the drugs are thereby disregarded. The "saturation" level, or the highest threshold-raising effect of which a drug is capable (6) provides a good base line for comparison of analgesic effectiveness. This method of comparison was not available to us; first, because the dangers of overdistention of the common bile duct limited us to $1,000 \mathrm{~mm}$. of water pressure, and second, because patient volunteers with common duct drainage, unlike healthy volunteers, are available for a limited time only. It was obvious from the onset that it would not be possible to study the same patients with all drugs and a great variety of dosage forms. We elected, therefore, to study all patients with as many drugs as possible and to confine studies, with a few exceptions, to only one dose and only one method of administration. The dose chosen was the average dose recommended by various sources for a $75 \mathrm{~kg}$. man. The toxic effects of the amounts employed were roughly comparable: in patients without tolerance the dose was one-half of the upper limit of safe usage.

The peak analgesic action for visceral pain occurred earlier than for integumental pain with all drugs tested. The mean peak action for morphine and meperidine at the end of 30 minutes was found about one-half hour earlier than their maximal action determined by the von Frey and HardyWolff-Goodell techniques, $(6,26)$. The other 
agents caused maximal relief of visceral pain 60 minutes after injection whereas their maximal effect on superficial pain was usually found after 90 minutes $(26,27)$. The measurable duration of action for visceral pain was about half that for skin pain. Wolff and associates found a return to the control threshold after seven hours with $8 \mathrm{mgm}$. morphine and $6.6 \mathrm{mgm}$. of methyldihydromorphinone (6). The short duration of action for visceral pain could not be attributed to a lesser overall effect of the drugs because of lower sensitivity of the method since the peak per cent elevation of skin pain due to radiant energy and of visceral pain due to distention were about the same.

Morphine was the most potent analgesic. The morphine derivatives were relatively four times as effective for superficial pain than for deep pain. Equivalent doses based on studies with the HardyWolff-Goodell and von Frey techniques were 30 mgm. morphine for $3 \mathrm{mgm}$. dihydromorphinone or $6.6 \mathrm{mgm}$. methyldihydromorphinone $(6,26)$. The equivalent doses for visceral pain were roughly $8 \mathrm{mgm}$. of morphine for above doses of the morphine derivatives.

The effect of codeine on visceral pain also compares unfavorably with its action on skin pain. For the latter, the equivalent dose of morphine and codeine was 8:60 (6). For visceral pain this ratio was approximately $3: 60$.

Since the introduction of meperidine, the evaluation of its analgesic power has been scaled downward somewhat. At present, it is thought to be about twice as effective as codeine and much less effective than morphine (28). This position of meperidine among other analgesics was confirmed. The more rapid onset of action and the shorter duration of action may have been partly due to the fact that meperidine, unlike all other drugs, was injected intramuscularly.

Considerable controversy exists over the effectiveness and duration of action of methadone. Originally it was thought to be twice as effective as morphine both in man and experimental animals (29). Its investigation with the WolffHardy-Goodell technique indicated that $5 \mathrm{mgm}$. was as potent as $15 \mathrm{mgm}$. of morphine (28). Clinical experience with methadone in the treatment of visceral pain revealed a somewhat lower potency. Troxil found it 1.5 times as active as morphine (30) and Denton and Beecher found no difference between methadone and morphine, mgm. for mgm., both with respect to speed of action and duration of effect (31). The present study confirmed methadone as a highly active analgesic agent. Present results differ in two respects from previous experience. From observation of patients, it was felt that $7.5 \mathrm{mgm}$. of methadone caused as much stupefaction, depression and drowsiness as $10 \mathrm{mgm}$. of morphine. This is in contrast to findings of others who observed no or only minimal sedation and narcosis $(28,29)$. Secondly, the duration of action of methadone was significantly greater than that of all other drugs tested. The shape of the time-action curve was therefore distinctly different. The total analgesic action of $7.5 \mathrm{mgm}$. methadone was 20 per cent greater than that of $10 \mathrm{mgm}$. morphine in spite of the latter's greater peak threshold raising ability.

The total lack of visceral analgesic activity of acetylsalicylic acid was striking. The long established clinical efficacy of acetylsalicylic acid in the treatment of headache, myalgia, arthralgia and other pain originating in integumental structures has been confirmed in the laboratory by quantitative skin threshold studies (32). A 35 per cent elevation of the skin pain threshold due to $0.3 \mathrm{Gm}$. of acetylsalicylic acid was equal to the effect of $45 \mathrm{mgm}$. of codeine. Harrison and Bigelow, using the ischemic muscle method, found a 25 per cent threshold elevation after $0.3 \mathrm{Gm}$. of acetylsalicylic acid (7). They concluded that acetylsalicylic acid is an effective analgesic agent for visceral pain. However, equally high and even higher threshold elevations were obtained with placebos. Furthermore, pain due to muscle ischemia should be grouped with pain from integumental structures and not with visceral pain.

Increasing doses of the same drug showed response patterns similar to those obtained from integumental structures. The "saturation" quantity or the smallest amount with which the highest threshold raising effect was obtained (6) was 16 $\mathrm{mgm}$. for morphine and between 100 and 200 mgm. for meperidine. Both these values were somewhat smaller than those found for skin pain. The "saturation" level, or highest threshold raising effect of which the drug was capable (6) was 120 per cent for morphine and 70 per cent for 
meperidine-also somewhat lesser analgesic effects than those observed with skin pain.

\section{SUMMARY AND CONCLUSIONS}

1. A quantitative method for measuring visceral pain thresholds by hydrostatic distention of the biliary ducts has been described. The method was used successfully in 32 of 40 patients who volunteered for these studies after surgical exploration of the common bile duct.

2. The painful sensation elicited by external elevation of the intrabiliary pressure was described as sharp or colicky by 47 per cent of the patients. The remainder reported dull pain or an ache. The pain was well localized in the right upper quadrant or epigastric region of the abdomen in 75 per cent of the patients and radiation to the back was noted by 25 per cent. For reliable end point determinations of the threshold the alertness of the patient at that time had to be assured.

3. The initial pain threshold in different patients varied from 90 to $800 \mathrm{~mm}$. of water. A slow rise of pain threshold was often noted in the same patients studied repeatedly from 14 days to seven months after operation. However, all measurements of pain thresholds of the same patients on the same day were found to be at least within \pm 10 per cent of their respective average values. In six patients studied at intervals during the course of 12 hours, the control threshold values showed a standard deviation of \pm 5.1 to $\pm 12.6 \mathrm{~mm}$. and a coefficient of variation of 0.67 to 3.82 per cent.

4. The administration of analgesic substances, with the exception of acetylsalicylic acid, invariably resulted in an elevation of the visceral pain threshold. Satisfactory time action curves were obtained on 157 occasions. The action of seven analgesic agents was studied. The doses used were : morphine, $10 \mathrm{mgm}$. ; codeine, $60 \mathrm{mgm}$. ; dihydromorphinone, $3 \mathrm{mgm}$.; methyldihydromorphinone, $7.5 \mathrm{mgm}$.; methadone, $7.5 \mathrm{mgm}$.; meperidine, $100 \mathrm{mgm}$.; and acetylsalicylic acid, $0.6 \mathrm{Gm}$.

5. The onset of action, shown by an elevation of the intrabiliary hydrostatic pressure tolerated without pain, was noted between seven and 15 minutes after injection with all drugs studied.

6. The peak threshold elevation was found 30 minutes after administration of morphine and meperidine and 60 minutes after all other agents. The mean peak threshold elevations in per cent together with the number of studies for each drug were as follows: morphine: 40 studies, 56 per cent, codeine: 27 studies, 12 per cent, dihydromorphinone: 11 studies, 42 per cent, methyldihydromorphinone: 7 studies, 46 per cent, methadone: 10 studies, 33 per cent, meperidine: 50 studies, 23 per cent, and acetylsalicylic acid: 13 studies, no threshold elevation.

7. The duration of action was five hours for morphine, four hours for codeine, dihydromorphinone and methyldihydromorphinone, six hours for methadone and three hours for meperidine.

8. The total analgesic action expressed by the area under the time-action curve in "per centhours" was 140 for morphine, 40 for codeine, 112 for dihydromorphinone, 98 for methyldihydromorphinone, 168 for methadone, 70 for meperidine and 0 for acetylsalicylic acid.

9. When morphine and meperidine were given in increasing doses, the total analgesic action increased in proportion to the dose up to $16 \mathrm{mgm}$. for morphine and $100 \mathrm{mgm}$. for meperidine. A further doubling of the dose to 32 and $200 \mathrm{mgm}$., respectively, caused only a 23 and 37 per cent respective increase in the total analgesic action.

10. The analgesic effect of various drugs was found to be inversely proportional to the initial pain threshold both in different patients and in the same patients studied at intervals.

11. Parenteral injections of placebos in eight patients were not reflected by a rise in the visceral pain threshold.

12. The severity of biliary and small intestinal spasm due to the analgesic agents studied was found to be in proportion to their analgesic activity.

13. Differences between visceral and integumental pain threshold responses to the various drugs were noted. The peak threshold-raising action for visceral pain occurred earlier than for superficial pain; the duration of action was shorter and the intensity of the analgesia was somewhat smaller for visceral pain. In the doses used, morphine showed the most powerful threshold raising activity and methadone showed the longest action. In contrast to integumental pain, acetylsalicylic acid had no analgesic activity for visceral pain. 


\section{REFERENCES}

1. Tainter, M. L., Pain. Ann. New York Acad. Sc., 1948, 51, 3.

2. Goetzl, F. R., Burrill, D. Y., and Ivy, A. C., A critical analysis. of algesimetric methods with suggestions for a useful procedure. Quart. Bull., Northwestern Univ. M. School, 1943, 17, 280.

3. Pfeiffer, C. C., Sonnenschein, R. R., Glassman, L., Jenney, E. H., and Bogolub, S., Experimental methods for studying analgesia. Ann. New York Acad. Sc., 1948, 51, 21.

4. Miller, L. C., A critique of analgesic testing methods. Ann. New York Acad. Sc., 1948, 51, 34.

5. Lewis, T., Pain. The Macmillan Co., New York, 1942, pp. 44-45.

6. Wolff, H. G., Hardy, J. D., and Goodell, H., Studies on pain. Measurement of the effect of morphine, codeine and other opiates on the pain threshold and an analysis of their relation to the pain experience. J. Clin. Invest., 1940, 19, 659.

7. Harrison, I. B., and Bigelow, N. H., Quantitative studies of visceral pain produced by the contraction of ischemic muscle. A. Research Nerv. \& Ment. Dis., Proc., 1943, 23, 154.

8. Lewis, T., Pickering, G. W., and Rothschild, P., Observations upon muscular pain in intermittent claudication. Heart, 1931, 15, 359.

9. Yonkman, F. F., Noth, P. H., and Hecht, H., Some pharmacologic features of Demerol. Proc. Central Soc. Clin. Research, 1942, 15, 89.

10. Ogilvie, W. H., Some notes on the surgical aspects of gall-stone disease. Guy's Hosp. Rep., 1925, 75, 78.

11. Schrager, V. L., and Ivy, A. C., Symptoms produced by distention of the gallbladder and biliary ducts; clinical and experimental study. Surg., Gynec. \& Obst., 1928, 47, 1.

12. Zollinger, R., Observations following distention of the gallbladder and common duct in man. Proc. Soc. Exper. Biol. \& Med., 1933, 30, 1260.

13. Zollinger, R., and Walter, C. W., Localization of pain following faradic stimulation of the common bile duct. Proc. Soc. Exper. Biol. \& Med., 1936, $35,267$.

14. Layne, J. A., and Bergh, G. S., An experimental study of pain in the human biliary tract induced by spasm of the sphincter of Oddi. Surg., Gynec. \& Obst., 1940, 70, 18.

15. White, J. C., and Smithwick, R. H., The Autonomic Nervous System. Anatomy, Physiology, and Surgical Application. The Macmillan Co., New York, 2nd ed., 1941.

16. McGowan, J. M., Butsch, W. L., and Walters, W., Pressure in the common bile duct of man; its relation to pain following cholecystectomy. J. A. M. A., 1936, 106, 2227.

17. McGowan, J. M., and Henderson, F. F., Prevention and management of pain following cholecystectomy. New England J. Med., 1940, 222, 948.
18. Gaensler, E. A., McGowan, J. M., and Henderson, F. F., A comparative study of the action of demerol and opium alkaloids in relation to biliary spasm. Surgery, 1948, 23, 211.

19. Gaensler, E. A., and McGowan, J. M., Biliary and small intestinal spasm due to synthetic analgesics methadone and methyldihydromorphinone (Metopon). Gastroenterology, 1950, 16, 484.

20. Gaensler, E. A., and McGowan, J. M., Activity of some newer spasmolytic agents on the biliary tract of man. A comparative study of isopropylnorepinephrine, adiphenine hydrochloride, methylaminoiso-octene, and khellin. J. Pharmacol. \& Exper. Therap., 1950, 99, 304.

21. Chapman, W. P., Herrera, R., and Jones, C. M., A comparison of pain produced experimentally in lower esophagus, common bile duct, and upper small intestine with pain experienced by patients with diseases of biliary tract and pancreas. Surg., Gynec. \& Obst., 1949, 89, 573.

22. Sarkisian, S., and McGowan, J. M., Personal communications.

23. Schumacher, G. A., The influence of inflammation of the pain threshold of the skin in man. A. Research Nerv. \& Ment. Dis., Proc., 1943, 23, 166.

24. Wolff, H. G., and Goodell, H., The relation of attitude and suggestion to the perception of and reaction to pain. A. Research Nerv. \& Ment. Dis., Proc., 1943, 23, 434.

25. Krueger, H., Action of morphine on the digestive tract. Physiol. Rev., 1937, 17, 618.

26. Seevers, M. H., and Pfeiffer, C. C., Study of analgesia, subjective depression, and euphoria produced by morphine, heroine, dilaudid, and codeine in normal human subject. J. Pharmacol. \& Exper. Therap., 1936, 56, 166.

27. Goodman, L., and Gilman, A., The Pharmacological Basis of Therapeutics. The Macmillan Co., New York, 1941, pp. 193-196.

28. Christensen, E. M., and Gross, E. G., Analgesic effects in human subjects of morphine, meperidine, and methadon. J. A. M. A., 1948, 137, 594.

29. Scott, C. C., Kohlstaedt, K. G., and Chen, K. K., Comparison of the pharmacologic properties of some new analgesic substances. Anesth. \& Analg., 1947, 26, 12.

30. Troxil, E. B., Clinical evaluation of analgesic methadon. J. A. M. A., 1948, 136, 920.

31. Denton, J. E., and Beecher, H. K., New analgesics. II. A clinical appraisal of the narcotic power of methadone and its isomers. J. A. M. A., 1949, 141, 1146.

32. Wolff, H. G., Hardy, J. D., and Goodell, H., Measurement of the effect on the pain threshold of acetylsalicylic acid, acetanilid, acetophenetidin, aminopyrine, ethyl alcohol, trichlorethylene, a barbiturate, quinine, ergotamine tartrate and caffeine: an analysis of their relation to the pain experience. J. Clin. Invest., 1941, $20,63$. 